\title{
Orthographically mediated inhibition effects: Evidence of activational feedback during visual word recognition
}

\author{
JASON F. REIMER, JOSEPH S. BROWN, and THOMAS C. LORSBACH \\ University of Nebraska, Omaha, Nebraska
}

\begin{abstract}
Models of visual word recognition that have adopted an interactive activation framework (e.g., Coltheart, Curtis, Atkins, \& Haller, 1993; Grainger \& Jacobs, 1996) assume that activation can spread from semantic to orthographic representations via a feedback mechanism during visual word recognition. The present study used a mediated priming paradigm to test whether such feedback exists and, if so, under what conditions. Participants named aloud targets that were preceded either by a semantically related prime (e.g., $d o g-c a t$ ) or by a prime that was related to the target via a mediating word (e.g., $c a t-\{\operatorname{dog}\}-b o g)$. Direct evidence of activational feedback was obtained in the form of orthographically mediated inhibition effects. These mediated inhibition effects are consistent with activationalfeedback and support models of visual word recognition that have adopted an interactive activation framework.
\end{abstract}

A number of prominent models of visual word recognition have adopted what has been referred to as the general interactive activation (IA) framework (e.g., Coltheart, Curtis, Atkins, \& Haller, 1993; Grainger \& Jacobs, 1996). The general IA framework is largely based on activation class models, such as McClelland and Rumelhart's (1981; Rumelhart \& McClelland, 1982) original IA model of visual word recognition and Morton's (1969, 1982) logogen model. There are four assumptions made within the general IA framework that are relevant to the present study. First, the processing of a visually presented word occurs at several distinct levels within the system, with each level being responsible for processing a separate component of the input. Second, the general IA framework assumes that lexical processing is an interactive process. Thus, both bottom-up and top-down betweenlevels processing jointly determines the final output. Third, interlevel interaction is made possible through the presence of between-levels pathways that connect lower levels with higher levels, as well as higher levels with lower levels. Between-levels connections were assumed to be both facilitatory and inhibitory in nature in the original conceptualization of the IA model (i.e., McClelland \& Rumelhart, 1981). However, more recent versions (e.g., McClelland, 1987) include only facilitatory between-

This research was conducted in partial fulfillment of a master's degree at the University of Nebraska at Omaha. These data were presented at the 37th Annual Meeting of the Psychonomic Society in Chicago. We are grateful to Derek Besner, Max Coltheart, Jonathan Grainger, Brigette Ryalls, and an anonymous reviewer for their helpful comments on an earlier version of this article. Correspondence concerning this article should be addressed to J. F. Reimer, Boys Town National Research Hospital, 555 North 30th Street, Omaha, NE 68131 (e-mail: reimerj@ boystown.org). levels connections. Fourth, within-level connections in the letter and word levels are inhibitory in nature, representing a form of intralevel lateral inhibition. Representations residing within these levels mutually compete for activation.

Descriptions concerning how visual word recognition is accomplished within a general IA framework indicate that upon entering the visual word recognition system, a target word is first processed within the letter level, where letter representations corresponding to the stimulus become activated (see Figure 1). Activation from the letter level is fed forward to the word level, where word representations become activated that contain letters that have been activated at the letter level. Within-level lateral inhibition aids in the selection of the correct word candidate that is to become the most active because stronger candidates inhibit the activation of weaker candidates. Finally, activation is fed forward to the semantic level, where the corresponding semantic representation of the word-level representation becomes activated. Facilitation within the semantic level results in the activation of the target word along with its semantic associates via spreading activation (e.g., Collins \& Loftus, 1975; Neely, 1977).

Activation is not only fed forward within the general IA framework, it is also allowed to be fed backward to lower levels. Specifically, word candidates that have become activated at the semantic level feed activation back to their corresponding representations residing in the word level via Pathway C (see Figure 1). Similarly, representations that are activated within the word level activate their corresponding representations in the letter level via Pathway D. The combination of both bottom-up and top-down facilitation and within-level competition ensures that the most appropriate representation at each level will be the most highly activated. 


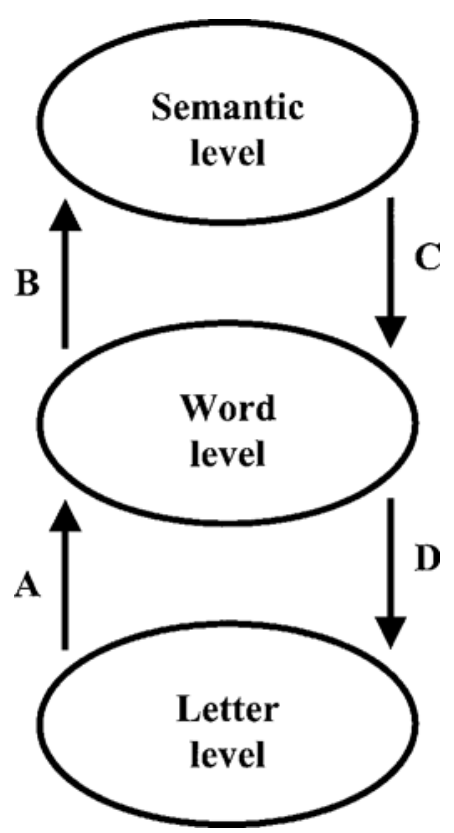

Figure 1. A general interactive activation framework. Note. From "Role of Set in Visual Word Recognition: Activation and Activation Blocking as Nonautomatic Processes," by J. A. Stolz and D. Besner, 1996, Journal of Experimental Psychology: Human Perception \& Performance, 22, p. 1168. Copyright 1996 by the American Psychological Association. Adapted with permission.

\section{THE PRESENT EXPERIMENT}

Activational feedback is a critical component of models of visual word recognition that have adopted the general IA framework (e.g., Borowsky \& Besner, 1993; Coltheart et al., 1993; Grainger \& Jacobs, 1996). Despite the central role that activational feedback plays within these models of visual word recognition, there currently exists little direct experimental evidence of activational feedback between the semantic level and the word level during visual word recognition. The primary goal of the present investigation, therefore, was to directly test the presence of activational feedback during visual word recognition. Specifically, the present investigation tested whether orthographic representations residing at the word level become activated as the result of activational feedback from the semantic level during visual word recognition.

The presence of activational feedback was tested through the use of a mediated priming paradigm. Rather than having a direct relationship (e.g., cat-dog), primes and targets in the mediated priming paradigm are related via a third mediating word (e.g., cat-[dog]-bog). For example, with the mediated prime-target word pair cat-bog, the prime (cat) is semantically related to a mediating nonpresented word ( $d o g)$, which is, in turn, both orthographically and phonologically related to the target (bog). If activation spreads from the semantic level to the word level, as is indicated by the IA framework, it is possible that either inhibitory or facilitatory mediated priming effects may be found when using the mediated priming paradigm. First, consider how the prime-target word pair cat-[dog]-bog might produce an inhibitory mediated priming effect when processed within the IA framework. The visual presentation of the prime, $c a t$, will ultimately result in the activation of its semantic representation residing at the semantic level. Through a spread of activation within the semantic level, the representations of semantic associates of cat (e.g., dog) will also become activated. According to the general IA framework, the presence of top-down connections allows activated semantic representations to feed activation back to their corresponding representations residing at the word and letter levels. Via these feedback connections, orthographic and letter representations of words that have not been visually presented to the reader (e.g., dog) become activated. When the target, bog, is presented, its corresponding letter nodes become activated and spread activation to word-level representations that contain those same letters (e.g., dog, bog). Thus, during target processing, the word-level representations of $d o g$ and $b o g$ will receive activation from the letter level and begin to mutually inhibit one another (along with all other representations at this level). However, because the word-level representation of $d o g$ had previously received activation from the semantic level during prime processing, at the time of target processing the amount of initial within-level inhibition flowing from $d o g$ 's representation will be greater than the amount of inhibition flowing from bog's representation. Consequently, the amount of time required to correctly select bog at the word level will be increased (relative to a control word) because it must first overcome lateral inhibition from a representation $(\operatorname{dog})$ that (1) had previously received activation from the semantic level during prime processing and (2) continues to receive activation from the letter level during target processing.

Next, consider how the same prime-target word pair, cat-[dog]-bog, might produce a facilitatory mediated priming effect when processed within the IA framework. As with the inhibition case, the prime, cat, will ultimately result in the activation of $d o g$ 's word-level representation via activational feedback from the semantic level. Activation will also feed back from the word level to the letter level, where the individual letter nodes $d, o$, and $g$ will become activated. Upon presentation of the target, bog, processing of the $o$ and $g$ letter nodes will be facilitated as a result of their preactivation. Consequently, the overall rate of processing of orthographically mediated targets (e.g., bog) will be facilitated, relative to control target words.

It is important to note that, regardless of the direction of the mediated priming effect that may be found when using the mediated priming paradigm, finding any mediated priming effect would not be possible without the 
presence of feedback connections between the semantic and the word levels. In the cases of both inhibition and facilitation, the amount of time required to process the target, $b o g$, at the word level would not be slowed or facilitated if the word level representation of $d o g$ had not been previously activated via activational feedback during prime processing. As a result, a direct test of activational feedback during visual word recognition can be conducted by measuring the speed and accuracy with which orthographically mediated targets are processed.

Testing the presence of feedback during visual word recognition is not only significant for models of visual word recognition that have adopted the general IA framework. Determining the presence of activational feedback bears theoretical importance for other visual word recognition models as well. For example, finding mediated priming effects within the mediated priming paradigm would be problematic for activation-verification models (e.g., Becker, 1979, 1985; Becker \& Killion, 1977; Paap, McDonald, Schvaneveldt, \& Noel, 1987; Paap, Newsome, McDonald, \& Schvaneveldt, 1982). Activationverification models typically do not include a mechanism that provides a link between mediated word pairs (catbog). Instead, the semantic set (containing semantic representations) and the sensory set (containing orthographic representations) present within activation-verification models are assumed to be independent of one another.

Although this is one of the first studies designed to directly test activational feedback within the IA framework, an earlier investigation by McNamara and Healy (1988) used the mediated priming paradigm in order to examine a similar mechanism contained in the Collins and Loftus (1975) semantic memory model. McNamara and Healy obtained inhibitory mediated effects under some conditions in their study but attributed these effects solely to postlexicaldecision processes, as opposed to activational feedback. However, the utilization of a lexical decision task and a self-paced silent reading task may partially account for their results. Specifically, because a lexical decision task and a self-paced silent reading task were used, the participants in McNamara and Healy's study were not required to verbalize the letter strings presented to them. In the absence of any verbal outputs, it was impossible for McNamara and Healy to assess whether the participants were correctly processing the words in each trial (e.g., incorrectly processing the target word bog as $d o g$ ). Given the nature of the word pairs used in the mediated condition, processing errors would have been easy for the participants to commit. If such processing errors were being committed by the participants in the McNamara and Healy study, even in some small proportion of the mediated trials, the facilitatory effect associated with these errors could have eliminated any existing inhibition effects that would have been present when the participants processed the stimuli correctly.

In light of the possible problems associated with using a lexical decision task or a self-paced silent reading task within the mediated priming paradigm, a naming task was used in the present investigation. There are two advantages to using the naming task. First, because participants are not required to perform binary decisions, a naming task eliminates the need for participants to determine the lexical status of words (Balota \& Lorch, 1986). Second, requiring participants to name stimuli aloud enables one to determine whether they have correctly processed the stimuli presented on each trial. Thus, processing errors caused by activational feedback can be measured.

Three mediated conditions were included in the present study: (1) an orthographically mediated condition in which there was an orthographic relationship between the target and the mediating word (e.g., mother-[father]lather), (2) a phonologically mediated condition in which there was a phonological relationship between the target and the mediating word (e.g., early-[late]-eight), and (3) a mixed condition in which there was both an orthographic and a phonological relationship between the target and the mediating word (cat-[dog]-bog). The orthographically mediated and the phonologicallymediated conditions were created in an attempt to separate the orthographic and the phonological components in the orthographically/ phonologically mediated condition. On the basis of the processing assumptions of the IA framework, if activation does spread from the semantic level to the word level, inhibitory or facilitatory mediated effects are expected to be found within the orthographically mediated and/or the orthographically/phonologically mediated conditions. Such mediated effects would be manifested in the response times (RTs) and/or error rates.

Finally, relatedness proportion (RP) was manipulated in the present study in order to assess its effect on mediated priming. RP here refers to the proportion of total prime-target word pairs that are semantically related in a test list (Stolz \& Neely, 1995). Two RP conditions were used: a high-RP condition (.50), in which $50 \%$ of the total prime-target word pairs were semantically related, and a low-RP condition (.20), in which $20 \%$ of the total prime-target word pairs were semantically related. By manipulating RP within the mediated priming paradigm, it is possible to directly test whether the activational feedback from the semantic level to the word level is modulated by RP, as was suggested by Stolz and Neely. Stolz and Neely suggested that the word recognition system may block the feedback of activation from the semantic level to the word level under low-RP conditions. If RP modulates feedback, mediated priming effects should be found when RP is high, but not when RP is low.

\section{METHOD}

\section{Participants}

Eighty college undergraduates enrolled in introductory psychology classes at the University of Nebraska at Omaha participated for partial course credit. Forty participants were randomly assigned to one of two RP conditions (.20 or .50). All the participants were native English speakers and possessed normal or corrected-to-normal vision. 


\section{Design}

A 4 (type of relation: semantically related vs. orthographically mediated vs. phonologically mediated vs. orthographically/ phonologically mediated) $\times 2$ (condition: experimental vs. control) $\times 2$ (RP: .20 vs. .50) mixed design was used. RP was varied between subjects, while condition and type of relation were varied within subjects. Both RT and accuracy were measured on each trial.

\section{Materials and Stimuli}

Stimuli were constructed by initially selecting 72 word pairs that exhibited a high degree of semantic relatedness in available word association norms (Keppel \& Strand, 1970; Marshall \& Cofer, 1970; Palmero \& Jenkins, 1964). In most instances, the second member of each pair served as the primary response in various word association norms (e.g., mother-father, early-late, cat-dog). Word triplets were then formed by adding a third word to each of the 72 semantically related word pairs. Although completely unrelated to the first word in each triplet, the third word of each triplet was orthographically related (e.g., mother-father-lather), phonologically related (e.g., early-late-eight), or both orthographically and phonologically related (e.g., cat-dog-bog) to the second word in the triplet. Of the 72 word triplets that were created, 24 contained an orthographic relationship, 24 contained a phonological relationship, and 24 contained both an orthographic and a phonological relationship between the second and the third words. The Appendix provides a complete listing of the 72 word triplets.

Four types of prime-target word pairs were then constructed from the 72 word triplets. With three types of word pairs, the primes and the targets had a mediated relationship (orthographically mediated, orthographically and phonologically mediated, or phonologically mediated), and with one type, the prime and the target had a semantic relationship. Twenty-four mediated prime-target word pairs were created for each of the three mediated conditions by using the first and the third words of the triplet, with the first word serving as the prime and the third word serving as the target (e.g., mother-lather, cat-bog, early-eight). In the orthographically mediated condition, at least $60 \%$ of the letters in the mediating and target words of each triplet matched and were in the same order $(M=$ $75 \%, S D=5 \%$ ), but the two words did not rhyme. Similarly, in the orthographically and phonologically mediated condition, at least $60 \%$ of the letters in the mediating and target words of each triplet matched and were in the same order $(M=73 \%, S D=7 \%)$. However, unlike the orthographically mediated condition, the two words rhymed in the orthographically and phonologically mediated condition. Finally, in the phonologically mediated condition, no more than $50 \%$ of the letters in the mediating and target words of each triplet matched and were in the same order $(M=34 \%, S D=12 \%)$. In addition, the two words rhymed. With the final type of word pair, the prime and the target had a semantic relationship. Seventy-two semantically related prime-target word pairs were created by using the first and second words of each word triplet, with the first word serving as the prime and the second serving as the target (e.g., mother-father, early-late, cat-dog). Thus, the experimental condition consisted of 144 experimental word pairs: 72 mediated word pairs and 72 semantically related prime-target word pairs.

Word pairs in the control condition were created by reassigning each prime to a different target within each of the three mediated conditions. Similarly, for the 72 semantically related word pairs, primes were reassigned to different unrelated targets. In all cases, the primes and targets that were used in the control condition did not possess a mediated or a semantic relationship (e.g., high-lather, black-rude, night-bog). Thus, the control condition consisted of 144 control word pairs: 72 controls for mediated word pairs and 72 controls for the semantically related word pairs.

From the total list of 288 prime-target word pairs, four test lists were constructed for each level of RP (.20 and .50). Four test lists were required in order to (1) avoid presenting the same word twice, either as a prime or as a target, and (2) ensure that each target word appeared equally often in both the experimental and the control conditions within a given type of relation. The four test lists in both the .20 and the .50 conditions consisted of 72 critical word pairs: 36 experimental prime-target word pairs and 36 control prime-target word pairs. For the experimental items, each list contained $18 \mathrm{se}-$ mantically related prime-target word pairs, 6 orthographically mediated word pairs, 6 phonologically mediated word pairs, and 6 orthographically/ phonologically mediated word pairs. For the control items, each of the four lists consisted of 18 word pairs (6 from each mediated type of relation) that served as controls for mediated word pairs and 18 word pairs that served as controls for the semantically related word pairs. From the critical items, the mediated and semantic priming effects were measured.

The level of RP (.20 vs. .50) was manipulated by varying the number of filler items included in the four test lists. For the .50 RP condition, 54 semantically related filler word pairs (obtained from a list of stimuli provided by Borowsky \& Besner, 1993) and 18 mediated filler word pairs (six orthographically mediated, six phonologically mediated, and six orthographically/ phonologically mediated) were used in addition to the 72 critical items, resulting in a total of 144 prime-target word pairs. Thus, for the $.50 \mathrm{RP}$ condition, $72(50 \%)$ of the 144 prime-target word pairs (18 experimental items and 54 filler items) were semantically related, and $72(50 \%)$ were either unrelated (36 controls) or mediated (18 experimental items and 18 fillers) word pairs.

In order to create the four test lists in the $.20 \mathrm{RP}$ condition, primes were reassigned to different unrelated targets with 43 of the 54 semantically related fillers. These 43 unrelated fillers, along with the remaining 11 semantically related fillers, were added to the 18 mediated fillers and the 72 critical items to create a total of 144 prime-target word pairs. Thus, for the .20 RP condition, $29(20 \%)$ of the 144 word pairs were semantically related (18 experimental items and 11 filler items), and 115 (80\%) were either unrelated (36 controls and 43 unrelated fillers) or mediated (18 experimental items and 18 fillers) word pairs. Therefore, the only difference between the test lists in the .50 RP condition and those in the .20 RP condition was the relative proportion of filler items. The order of presentation of the prime-target word pairs within all the test lists was random.

Twenty-four practice items were also constructed. Of these 24 practice items, 12 were semantically related, and 12 were mediated prime-target word pairs. None of the words contained in the practice items appeared in the test lists.

\section{Procedure}

The presentation of stimuli and the recording of both accuracy and RT were accomplished with a Gateway 2000 386/SX microcomputer that was controlled with Micro Experimental Laboratory software (Schneider, 1988, 1990). The RTs of each participant were obtained by interfacing a microphone with the microcomputer. A response box was also interfaced with the computer and was used to record the accuracy of each response. The stimuli were presented in the center of a 14-in. color monitor, using white lowercase letters on a black background.

The participants were tested individually in a quiet, well-lighted room. Each participant was seated approximately $50 \mathrm{~cm}$ from the computer monitor and was instructed to hold the microphone approximately $2 \mathrm{~cm}$ from his or her mouth. The participants were presented with 24 practice trials and 144 test trials. Each trial began with the presentation of a centrally located fixation cross, which remained visible until the participant pressed the space bar on the computer keyboard. Once the space bar was pressed, the fixation cross disappeared and was replaced immediately by the prime word, which remained visible for $500 \mathrm{msec}$. A 300-msec interstimulus interval (ISI) followed each prime, during which the fixation cross was again presented. Immediately following the 300-msec ISI, the 
Table 1

Mean Correct Response Times (RTs; in Milliseconds), Error Rates (\% E), and Priming Effects by Type of Relation and Condition

\begin{tabular}{|c|c|c|c|c|c|c|c|c|c|c|c|c|}
\hline \multirow[b]{4}{*}{ Condition } & \multicolumn{12}{|c|}{ Type of Relation } \\
\hline & \multicolumn{3}{|c|}{ Semantic } & \multicolumn{3}{|c|}{ Ortho/Phono } & \multicolumn{3}{|c|}{ Ortho } & \multicolumn{3}{|c|}{ Phono } \\
\hline & \multicolumn{2}{|c|}{ RT } & \multirow[b]{2}{*}{$\% \mathrm{E}$} & \multicolumn{2}{|c|}{ RT } & \multirow[b]{2}{*}{$\% \mathrm{E}$} & \multicolumn{2}{|c|}{ RT } & \multirow[b]{2}{*}{$\% \mathrm{E}$} & \multicolumn{2}{|c|}{ RT } & \multirow[b]{2}{*}{$\% \mathrm{E}$} \\
\hline & $M$ & $S D$ & & $M$ & $S D$ & & $M$ & $S D$ & & $M$ & $S D$ & \\
\hline Control & 541 & 59.2 & 1.3 & 550 & 72.7 & 8.2 & 549 & 66.3 & 6.4 & 547 & 63.4 & 6.5 \\
\hline Experimental & 515 & 52.8 & 1.0 & 567 & 81.4 & 7.6 & 563 & 83.0 & 9.4 & 548 & 72.5 & 6.6 \\
\hline Priming effect & +26 & & +0.3 & -17 & & +0.6 & -14 & & -3.0 & -1 & & -0.1 \\
\hline
\end{tabular}

Note-Ortho, orthographic; Phono, phonological; priming effect = control - experimental difference.

target word appeared. The participants were instructed to read the first word (prime) in each trial silently and to name aloud the second word (target) as quickly as possible, without sacrif icing accuracy. After the accuracy of the response was entered by the experimenter, feedback was given to the participant in the upper left-hand corner of the computer monitor. The entire set of 144 test trials required approximately $30 \mathrm{~min}$ to complete.

\section{RESULTS}

Mean RTs and error rates were computed for each subject and were submitted to a 2 (RP: .20 vs. .50) $\times 2$ (condition: experimental vs. control) $\times 4$ (type of relation: semantically related vs. orthographically mediated vs. phonologically mediated vs. orthographically/ phonologically mediated) mixed design analysis of variance. Latencies associated with trials in which the voice key was triggered by noise or there was a failure of the voice key to register were excluded (i.e., latencies $<150$ $\mathrm{msec}$ and $>1,500 \mathrm{msec}$ ). Six trials out of a total of 5,300 correct trials were excluded. In addition, as a result of an oversight in stimulus construction, one item in the orthographically/phonologically mediated condition ( judge-jury-bury) was excluded from all the subsequent analyses. Therefore, 23 , as opposed to 24 , items were used in the orthographically/phonologically mediated condition. An alpha level of .05 was used for all the statistical tests.

\section{Response Times}

Only correct responses were included in the analysis of the RT data. The three-way interaction involving RP, condition, and type of relation was not significant $(F<1)$. The two-way interaction involving condition and type of relation was significant $\left[F(3,234)=8.968, M S_{\mathrm{e}}=\right.$ 1,701.145; see Table 1]. Planned comparisons were performed with each type of relation to determine whether the RTs in the experimental and the control conditions differed. For the semantically related word pairs, the experimental condition yielded significantly faster RTs $(M=515 \mathrm{msec})$ than did the control condition $[M=$ $\left.541 \mathrm{msec} ; F(1,234)=16.064, M S_{\mathrm{e}}=1,707.145\right]$. In contrast, for the orthographically/phonologically mediated word pairs, RTs in the experimental condition were reliably slower $(M=567 \mathrm{msec})$ than the RTs in the control condition $\left[M=550 \mathrm{msec} ; F(1,234)=6.886, M S_{\mathrm{e}}=\right.$ 1,701.145]. Likewise, in the orthographically mediated condition, the experimental condition $(M=563 \mathrm{msec})$ yielded significantly slower RTs than did the control condition $\left[M=549 \mathrm{msec} ; F(1,234)=4.089, M S_{\mathrm{e}}=1,701.145\right]$. However, for the phonologically mediated condition, the experimental and control conditions were not significantly different $(F<1)$.

In addition to the significant condition $\times$ type of relation interaction, a main effect of type of relation was found $\left[F(3,234)=18.878, M S_{\mathrm{e}}=1,630.506\right]$. This main effect was not further examined, because different target words were used in each of the four types of relation. No other significant effects were found.

\section{Error Rates}

Neither the RP $\times$ condition $\times$ type of relation interaction $(F<1)$ nor the condition $\times$ type of relation interaction [see Table $1 ; F(3,234)=1.211, M S_{\mathrm{e}}=0.009$ ] was significant. Planned comparisons were again conducted in order to determine whether the error rates in the experimental and the control conditions differed significantly with each type of relation. The error rates in the experimental and the control conditions did not differ from each other with semantically related word pairs, orthographically/phonologically mediated word pairs, or phonologically mediated word pairs (all $F_{\mathrm{s}}<1$ ). However, the experimental condition in the orthographically mediated condition yielded a significantly higher error rate $(M=9.4 \%)$ than did its corresponding control condition $\left[M=6.4 \% ; F(1,234)=3.913, M S_{\mathrm{e}}=0.009\right]$. The only remaining significant effect involved type of relation $\left[F(3,234)=16.854, M S_{\mathrm{e}}=0.010\right] .^{1}$

\section{DISCUSSION}

The IA framework includes connections that allow activation to spread from the semantic level to the word level during visual word recognition. The present study provided evidence of this backward spread of activation in the form of mediated inhibition effects with both RTs and error rates in the orthographically mediated condition and with RTs in the orthographically/phonologically mediated condition. ${ }^{2}$ 
The claim that the mediated inhibition effects obtained in the present study provide direct evidence of a spread of activation from the semantic level to the word level is based on the nature of the prime-target relationship in the orthographically mediated and the orthographically/ phonologically mediated conditions. In order for primes to affect the processing of targets in these mediated conditions, two separate spreads of activation must take place. First, the presentation of the prime must initiate a spread of activation within the semantic level, whereby the prime's semantic-level representation activates its semantic associates. This spread of activation is necessary for semantic priming to be observed, because representations residing at the word level are not associatively linked within the IA framework. Second, a backward spread of activation from the semantic level to the word level must be present, whereby activated semantic representations of mediating words are able to activate their corresponding word-level representations. This backward spread of activation was necessary for mediated priming, because mediating words (e.g., dog) and targets (e.g., bog) were not semantically related. Unless the word-level representations of mediating words became activated in addition to their semantic-level representations, it would not be possible for primes to have affected the processing of targets. As a result, the mediated inhibition effects found in the present experiment appear to raise problems for models of visual word recognition that do not allow activated semantic representations to feed activation back to their corresponding word-level representations (e.g., activationverification models).

The mediated inhibition effects found in the present experiment are comparable with other orthographic priming effects that have been reported in the literature. For example, Grainger (1990; see also Colombo, 1986) found small inhibitory priming effects when targets were directly preceded by orthographically related primes in a naming task. Interestingly, similar mediated orthographic inhibition effects were found in the present experiment, despite the fact that mediating words were not visually presented to the participants. Specifically, in both experiments, the activation of representations at the word level slowed the processing of orthographically related targets. However, word-level representations in the Grainger study were activated as a result of direct visual input, whereas word-level representations in the present experiment were activated via activational feedback from the semantic system.

Previously in this article, mediated facilitation and mediated inhibition effects were presented as two potential outcomes for orthographically mediated priming within the IA framework. One factor that may play a large role in determining which of these two outcomes is found is the relative strength of the within-level inhibitory connections and the between-levels facilitatory connections present within the IA framework. If within-level connections are stronger than between-levels connections, representations (e.g., $d o g$ ) at the word level that continue to receive activation from the letter level during target pro- cessing (e.g., bog) would strongly inhibit the target's word-level representation as it continues to receive bottomup activation. Weaker between-levels connections would, on the other hand, feed relatively smaller amounts of facilitation from activated letter representations (e.g., $o, g$ ) to the target's word-level representation (e.g., bog). In this case, the net effect would be inhibition. In contrast, if between-levels connections are stronger than within-level connections, the opposite effect would be produced. Relatively stronger between-levels connections would feed large amounts of facilitation from activated letter representations to the target's word-level representation. This facilitation would be strong enough to overcome the relatively weaker within-level inhibition spreading from competing representations (e.g., $d o g$ ). In this case, the net effect would be facilitation.

In order to test this scenario, simulations of the present experiment were run using the DRC model of visual word recognition and reading aloud (Coltheart et al., 1993). The DRC model was able to produce both mediated facilitation and inhibition effects, depending on the value of a parameter used to specify the amount of withinlevel inhibition present in the word level (Max Coltheart, personal communication, April 21, 1999). When the parameter was set to its standard value of .06, mediated facilitation effects were produced. However, when the parameter's value was increased to .475 , mediated inhibition effects were produced. It should be pointed out that although the DRC is able to simulate the mediated inhibition effects found in the present experiment, it can only do so when the within-level inhibition parameter is changed from its standard value (.06) to a much higher value (.475). Unfortunately, changing the value of this parameter to higher levels eliminates the ability of the DRC model to account for other well-established reading effects (e.g., the effect of neighborhood size on nonword naming; Laxon, Masterson, Pool, \& Keating, 1992). It is possible, however, that the relative strength of withinlevel and between-levels connections in the DRC may actually change in response to various task demands, as opposed to being fixed. For example, within-level connection strength may increase in tasks that result in the activation of multiple word candidates within a given level in order to facilitate the selection of the correct word candidate.

Even though the use of a naming task in the present study makes it unlikely that the mediated inhibition effects found in the present experiment occurred during postlexical decision processing (see McNamara \& Healy, 1988), one might argue that the inhibition occurred during postlexical processing at the output stage of the word recognition system. Although the present study cannot completely rule out this alternate explanation, it seems unlikely. Postlexical response stages of visual word recognition (e.g., the phonological output lexicon) are generally regarded as being responsible for the activation of phonological strings for verbal output (e.g., Besner \& Smith, 1992). Finding inhibition in the orthographically and the orthographically/phonologically mediated con- 
ditions and not in the phonologically mediated condition seems inconsistent with the argument that postlexical response competition during output processing was responsible for slower and less accurate processing.

Another possible account of the mediated inhibition effects found in the present experiment is that when the participants were presented with orthographically and orthographically/phonologically mediated word pairs, they were expecting the target word to be a semantic associate of the prime (e.g., dog), as opposed to an orthographically similar word (e.g., bog). As a result, the participants may have conducted a double-check on orthographically mediated targets, slowing overall processing speed for this type of target word. This account, however, may simply represent a general description of the previous account that was detailed in the introduction to this article concerning how orthographically mediated targets are processed within the IA framework. Specifically, for orthographically mediated word pairs, the participants may have been expecting the word $d o g$ when given the prime, cat, because $d o g$ 's word- and letter-level representations received activation from the semantic system. Given this expectation, the participants may have engaged in doublechecking during target processing in order to provide sufficient bottom-up activation to bog's orthographic representation to overcome the within-level inhibition flowing from dog. Most important, such double-checking during target processing would not be required in the first place if $d o g$ 's orthographic representation had not been activated via feedback from the semantic system.

One final note should be made concerning the failure to obtain inhibition effects within the phonologically mediated condition. Some theorists have argued that lexical access is largely based on phonology (e.g., Frost, 1998; Lukatela \& Turvey, 1994a, 1994b). For example, phonological codes have been argued to play a central role in lexical access by providing the initial constraints placed on lexical access and "setting the stage" for subsequent orthographic constraints (Lukatela \& Turvey, 1994a). In addition, it has been suggested that skilled readers may use phonological codes only when accessing their lexical knowledge (Lukatela \& Turvey, 1994b). If phonological codes are accessed during the early stages of word recognition, evidence of such access should have been observed within the phonologically mediated condition in the present study. However, no phonologically mediated inhibitory effects were found. Although there are difficulties in interpreting null results, the failure to find evidence of initial phonological access in the present study appears problematic for phonologically based theories of word recognition.

\section{Relatedness Proportion and Activational Feedback}

Stolz and Neely (1995) have indicated that feedback does not necessarily have to be automatic in nature, suggesting that under low-RP conditions, feedback may not occur. Despite the fact that RP previously has been found to affect semantic priming (e.g., den Heyer, 1985; Keefe \& Neely, 1990), there was no significant effect of RP in the semantically related condition in the present study. However, RP did numerically reduce the semantic priming effects from $+32 \mathrm{msec}$ in the $.50 \mathrm{RP}$ condition to $+19 \mathrm{msec}$ in the $.20 \mathrm{RP}$ condition. This suggests that although RP had some effect on semantic priming, the effect was not large enough to be detected, given the relatively small amount of statistical power available in the present experiment. By using a much larger sample size ( $N=312$ in Experiment 1 and $N=309$ in Experiment 2), Stolz and Neely utilized greater statistical power to detect the effects of RP. In any event, because RP did not have a reliable effect on semantic priming, it is difficult to interpret the absence of any effects of RP on mediated priming.

\section{Conclusions}

On the basis of the mediated inhibition effects that were obtained in the present study, direct evidence was found that activation spreads from the semantic level to the word level during visual word recognition, as is assumed by the IA framework. Because mediated effects were not found with phonologically mediated word pairs, the present data indicated that lateral inhibition within the word level was responsible for the slower and less accurate processing of orthographically mediated targets. Investigations are presently underway to further examine the effect of RP on feedback and to determine the precise timecourse of feedback during visual word recognition.

\section{REFERENCES}

Balota, D. A., \& LoRch, R. (1986). Depth of automatic spreading activation: Mediated priming effects in pronunciation but not in lexical decision. Journal of Experimental Psychology: Learning, Memory, \& Cognition, 12, 336-345.

BeCKER, C. A. (1979). Semantic context and word frequency effects in visual word recognition. Journal of Experimental Psychology: Human Perception \& Performance, 5, 252-259.

BECKER, C. A. (1985). What do we really know about context effects? In D. Besner, T. G. Waller, \& E. M. MacKinnon (Eds.), Reading research: Advances in theory and practice (pp. 125-166). San Diego: Academic Press.

BeCKeR, C. A., \& Killion, T. H. (1977). Interaction of visual and cognitive effects in word recognition. Journal of Experimental Psychology: Human Perception \& Performance, 3, 389-401.

Besner, D., \& Smith, M. C. (1992). Models of visual word recognition: When obscuring the stimulus yields a clearer view. Journal of Experimental Psychology: Learning, Memory, \& Cognition, 18, 468482.

Borowsky, R, \& BESNER, D. (1993). Visual word recognition: A multistage activation model. Journal of Experimental Psychology: Learning, Memory, \& Cognition, 19, 813-840.

Collins, A. M., \& Loftus, E. F. (1975). A spreading-activation theory of semantic processing. Psychological Review, 82, 407-428.

Colombo, L. (1986). Activation and inhibition with orthographically similar words. Journal of Experimental Psychology: Human Perception \& Performance, 12, 226-324.

Coltheart, M., Curtis, B., Atkins, P., \& Haller, M. (1993). Models of reading aloud: Dual-route and parallel-distributed-processing approaches. Psychological Review, 100, 589-608.

DEN HeYER, K. (1985). On the nature of the proportion effect in semantic priming. Acta Psychologica, 61, 17-36.

Frost, R. (1998). Toward a strong phonological theory of visual word 
recognition: True issues and false trails. Psychological Bulletin, 123, 71-99.

GRAINGER, J. (1990). Word frequency and neighborhood frequency effects in lexical decision and naming. Journal of Memory \& Language, 29, 228-244.

Grainger, J., \& JACOBS, A. M. (1996). Orthographic processing in visual word recognition: A multiple read-out model. Psychological Review, 103, 518-565.

Keefe, D. E., \& Neely, J. H. (1990). Semantic priming in the pronunciation task: The role of prospective prime-generated expectancies. Memory \& Cognition, 18, 289-298.

Keppel, G., \& Strand, B. Z (1970). Free-association responses to the primary purposes and other responses selected from the PalmeroJenkins norms. In L. Postman \& G. Keppel (Eds.), Norms of word associations (pp. 177-240). New York: Academic Press.

Laxon, V. J., Masterson, J., Pool, M., \& Keating, C. (1992). Nonword naming: Further exploration of the pseudohomophoneeffect in terms of orthographic neighborhood size, graphemic changes, spelling-sound consistency, and reader accuracy. Journal of Experimental Psychology: Learning, Memory, \& Cognition, 18, 730-748.

Lukatela, G., \& Turvey, M. T. (1994a). Visual lexical access is initially phonological: 1 . Evidence from associative priming by words, homophones, and pseudohomophones. Journal of Experimental Psychology: General, 123, 107-128.

Lukatela, G., \& Turvey, M. T. (1994b). Visual lexical access is initially phonological: 2 . Evidence from phonological priming by homophones and pseudohomophones. Journal of Experimental Psychology: General, 123, 331-353.

Marshall, G. R, \& Cofer, C. N. (1970). Single-word free-association norms for 328 responses from the Connecticut cultural norms for verbal items in categories. In L. Postman \& G. Keppel (Eds.), Norms of word associations (pp.177-240). New York: Academic Press.

McClelland, J. L. (1987). The case for interactionism in language processing. In M. Coltheart (Ed.), Attention and performance XII: The psychology of reading (pp. 3-35). Hillsdale, NJ: Erlbaum.

McClelland, J. L., \& Rumelhart, D. E. (1981). An interactive activation model of context effects in letter perception: I. An account of basic findings. Psychological Review, 88, 375-407.

McNamara, T. P., \& Healy, A. F. (1988). Semantic, phonological, and mediated priming in reading and lexical decisions. Journal of Experimental Psychology: Learning, Memory, \& Cognition, 14, 398-409.

MorTon, J. (1969). Interaction of information in word recognition. Psychological Review, 76, 165-178.

Morton, J. (1982). Disintegrating the lexicon: An information processing approach. In J. Mehler, E. C. T. Walker, \& M. Garrett (Eds.), Perspectives on mental representation (pp. 89-109). Hillsdale, NJ: Erlbaum.

NeELy, J. H. (1977). Semantic priming and retrieval from lexical memory: Role of inhibitionless spreading activation and limited-capacity attention. Journal of Experimental Psychology: General, 106, 226-254.

O'Seaghdha, P. G., \& Marin, J. W. (1997). Mediated semanticphonological priming: Calling distant relatives. Journal of Memory \& Language, 36, 226-252.

PaAp, K. R., McDonald, J. E., Schvaneveldt, R. W., \& Noel, R. W. (1987). Frequency and pronounceability in visually presented naming and lexical decision tasks. In M. Coltheart (Ed.), Attention and performance XII: The psychology of reading (pp. 221-243). Hillsdale, NJ: Erlbaum.

Paap, K. R., Newsome, S. L., McDonald, J. E., \& Schvaneveldt, R. W. (1982). An activation-verification model for letter and word recognition: The word-superiority effect. Psychological Review, 89, 573-594.

Palmero, D. S., \& Jenkins, J. J. (1964). Word association norms: Grade school through college. Minneapolis: University of Minnesota Press.
Rumelhart, D. E., \& McClelland, J. L. (1982). An interactive activation model of context effects in letter perception: II. The contextual enhancement effect and some tests and extensions of the model. Psychological Review, 89, 60-94.

SCHNEIDER, W. (1988). Micro Experimental Laboratory: An integrated system for IBM-PC compatibles. Behavior Research Methods, Instruments, \& Computers, 20, 206-217.

SCHNEIDER, W. (1990). MEL user's guide: Computer techniques for real time experimentation. Pittsburgh: Psychology Software Tools.

Stolz, J. A., \& BeSner, D. (1996). Role of set in visual word recognition: Activation and activation blocking as nonautomatic processes. Journal of Experimental Psychology: Human Perception \& Performance, 22, 1166-1177.

Stolz, J. A., \& Neely, J. H. (1995). When target degradation does and does not enhance semantic context effects in word recognition. Journal of Experimental Psychology: Learning, Memory, \& Cognition, 21, 596-611.

\section{NOTES}

1. Analyses testing against item variability were also performed on the RT and error rate data. For the semantically related word pairs, planned comparisons revealed that the experimental condition yielded significantly faster RTs than did the control condition $\left[F_{2}(1,139)=\right.$ $\left.12.773, M S_{\mathrm{e}}=1,857.927\right]$. However, a significant difference between the experimental and the control conditions was not found with orthographically/phonologically mediated word pairs $\left[F_{2}(1,139)=2.017\right.$, $\left.M S_{\mathrm{e}}=1,857.927, p<.16\right]$, orthographically mediated word pairs $\left(F_{2}<1\right)$, or phonologically mediated word pairs $\left(F_{2}<1\right)$. With the error rate data, planned comparisons revealed no significant differences between the experimental and the control conditions with any of the four types of word pairs.

Given the heavy constraints placed on stimulus generation in an experiment such as the one we conducted, the failure of the mediated inhibition effects to generalize across items bears little importance, for at least three reasons. First, the stimuli were not randomly selected. Second, it was nearly impossible to control for a number of stimulus variables (i.e., word frequency, the relationship of targets to other items in the test list, etc.) that may have increased error variance among our stimuli. For example, some of the target words in the orthographically mediated word pairs had consistent spelling-to-sound correspondences, whereas others had inconsistent spelling-to-sound correspondences. An analysis was conducted to determine whether spelling-to-sound consistency had any influence on the mediated inhibition effects in this condition. Although a statistically significant orthographically mediated inhibition effect was not found for consistent or inconsistent target words, numerically larger mediated effects were found with consistent targets $(-27 \mathrm{msec} ;-5.1 \%$ errors $)$ than with inconsistent targets $(-13.7 \mathrm{msec}$; $-2.7 \%$ errors). Third, regardless of whether mediated inhibition effects generalize across all the items used in the present experiment, the fact remains that at least one version of the IA framework (i.e., the dualroute cascaded [DRC] model of visual word recognition; Coltheart et al., 1993) failed to simulate the present mediated inhibition effects when using these same items (Max Coltheart, personal communication, August 13, 1997). Finally, it should be noted that other investigators have encountered similar problems associated with item variability when using similar mediated priming paradigms (e.g., O'Seaghdha \& Marin, 1997).

2. In order to determine whether the mediated inhibition effects that were obtained in the present study could be replicated, a second experiment was conducted. The second experiment was identical to the present experiment, with the exception that an RP of . 80 was used. Evidence of activational feedback was obtained in the second experiment in the form of mediated inhibition effects in the error rate data, but not in the RT data. 
APPENDIX

The 72 Word Triplets

\begin{tabular}{lll}
\hline Orthographically/Phonologically Mediated & Orthographically Mediated & Phonologically Mediated \\
\hline cat-dog-bog & mother-father-lather & heavy-light-quite \\
doctor-nurse-curse & high-low-now & bitter-sweet-suite \\
night-day-hay & lemon-sour-tour & train-track-plaque \\
pepper-salt-malt & wish-want-pant & table-chair-rare \\
sleep-bed-led & tulip-flower-blower & knife-blade-raid \\
hammer-nail-wail & dry-wet-wit & needle-thread-said \\
slow-fast-cast & music-sound-wound & sheep-wool-pull \\
shallow-deep-seep & house-home-hole & hint-clue-crew \\
web-spider-cider & cold-hot-hut & foot-shoe-blue \\
square-round-pound & justice-law-low & live-die-rye \\
over-under-blunder & uncle-aunt-punt & book-read-seed \\
sweep-broom-groom & bread-butter-batter & early-late-eight \\
water-drink-brink & scissors-cut-cute & smooth-rough-cuff \\
loud-soft-loft & thief-robber-rubber & head-hair-bear \\
long-short-port & always-never-fever & sell-buy-lie \\
hill-mountain-fountain & hard-soft-sift & thirsty-water-daughter \\
girl-boy-joy & brush-comb-tomb & eating-food-rude \\
judge-jury-bury & green-grass-gross & black-white-fight \\
lost-found-hound & faster-slower-tower & color-red-dead \\
speak-talk-balk & up-down-dawn & robin-bird-heard \\
city-town-gown & anger-mad-wad & lamp-shade-laid \\
swift-fast-past & crack-break-freak & hand-foot-put \\
carpet-floor-poor & north-south-youth & stove-hot-bought \\
old-new-pew & in-out-rut & open-close-toes \\
\hline
\end{tabular}

(Manuscript received November 24, 1998;

revision accepted for publication December 20,1999.) 